\title{
Kernos
}

Revue internationale et pluridisciplinaire de religion grecque antique

18 | 2005

Varia

\section{Françoise FRONTISI-DUCROUX, L'homme-cerf et la femme-araignée}

\section{Véronique Dasen}

URL : http://journals.openedition.org/kernos/1741

DOI : 10.4000/kernos. 1741

ISSN : 2034-7871

\section{Éditeur}

Centre international d'étude de la religion grecque antique

\section{Édition imprimée}

Date de publication : 1 janvier 2005

Pagination : $555-556$

ISSN : 0776-3824

\section{Référence électronique}

Véronique Dasen, « Françoise frontisi-ducroux, L'homme-cerf et la femme-araignée », Kernos [En ligne], 18 | 2005, mis en ligne le 24 mai 2011, consulté le 21 septembre 2020. URL : http:// journals.openedition.org/kernos/1741 ; DOI : https://doi.org/10.4000/kernos.1741 
indéniable, mais les auteurs y définissent deux types de chair, féminine et masculine, dont la différence est radicalisée par la présence de l'utérus, organe féminin - et maternel - par excellence.

Véronique Dasen

(Université de Fribourg)

Françoise Frontisi-DuCroux, L’homme-cerf et la femme-araignée, Paris, Gallimard, 2003. 1 vol. $16,5 \times 21$ cm, 300 p., 70 ill. (Le Temps des images). ISBN : 2-07-076655-1.

Ce livre important nous mène au cour du fonctionnement de l'imaginaire collectif grec au travers des déclinaisons presque infinies des métamorphies humaines et divines dans la mythologie classique. Face à la profusion des récits, Fr. FrontisiDucroux s'est centrée sur les histoires qui font l'objet de représentations figurées, sans négliger les récits parallèles dépourvus de version iconographique ou qui ne sont connus que par les images. Avec beaucoup de finesse, l'A. fait patiemment émerger de la confrontation du système verbal avec les procédés de réthorique picturale les spécificités des catégories mentales et symboliques grecques. Les principaux axes de réflexion s'articulent autour de la perméabilité des frontières entre l'humain, l'animal, le végétal et le minéral, traduite par différentes formes d'hybridation, parfois incomplètes ou doublées d'un changement de sexe, autour des rapports entre la féminité et l'animalité, le désir et la bestialité, enfin de la métamorphose comme expression particulière d'une temporalité perçue non comme un continuum mais comme une succession de stades distincts.

Les récits examinés sont essentiellement livrés par des auteurs grecs, mais sans faire l'économie d'Ovide, qui le premier utilise le mot grec Metamorphoseon dans le titre de son poème Les métamorphoses. Conservatoire de récits disparus, son recueil est précieux à plus d'un titre, notamment pour sa part de réélaboration qui permet d'approcher d'autres façons culturelles de penser le corps et l'hybridation.

Le livre est découpé en six chapitres qui tournent chacun autour d'un mythe principal et d'une thématique. Le premier chapitre explore l'hybridité et la polymorphie des créatures qui hantent les mers, tels Nérée, sa fille Thétis, Protée, Glaucos et Métis. Leur métamorphie n'est pas la conséquence d'un accident ni d'un acte volontaire, mais inhérente à leur nature, changeante et fluide comme l'eau. Leur passage d'une forme à l'autre est traduite visuellement par des formes composites juxtaposant des appendices animaux (poisson, lion, panthère, chèvre, serpent). L'épisode de la lutte de Thétis et Pélée détient une valeur paradigmatique. Il rappelle la fonction profonde du mariage, maîtriser la nature féminine en fixant son instabilité foncière. - Le deuxième chapitre explore autour du mythe de Circé les limites d'une bestialisation qui ne prive pas de conscience humaine les hommes enfermés dans une enveloppe animale. Les imagiers inventent des assemblages composites, greffant des parties animales sur des parties humaines, usant de métonymie visuelle pour rendre visible la transformation des victimes. L'emploi constant de l'aoriste pour décrire le phénomène traduit l'impossible représentation du temps de la métamorphose, insaississable pour les mortels; la valeur ponctuelle de l'action verbale renvoie à l'instantanéité de l'action divine. - Le troisième chapitre interroge le statut de la vision par le biais du mythe d'Actéon qui bascule dans l'animalité à cause de son voyeurisme. Chasseur devenu proie, il est dévoré par ses chiens. Sa métamorphose en cerf est-elle réelle ou les chiens sont-ils sujets d'une hallucination? Le sort d'Actéon renvoie à celui de Tirésias qui change de sexe en punition de son regard transgressif. 
Les transformations de Zeus constituent l'objet du quatrième chapitre. Ses métamorphoses et celles de ses amantes mettent en évidence l'animalité de la femme et la bestialisation qu'elle provoque chez le mâle qui la désire. - Les mythes de Niobé et de Méduse permettent d'aborder, dans un cinquième chapitre, les qualités symboliques et métaphoriques de la pétrification, associée au thème de l'invisibilité, de la mort et de la souffrance causée par l'absence. Figée dans une douleur paralysante sur la tombe de ses enfants, Niobé se transforme en monument funéraire. Sous le pinceau des imagiers italiotes, elle devient tantôt sa propre statue et sèma des disparus, tantôt perd complètement forme humaine en se muant en stèle ou tumulus. Ces motifs se retrouvent concentrés chez Méduse et ses sœurs, créatures hybrides au regard pétrifiant.

Ce parcours foisonnant se termine dans l'espace des femmes où la voix silencieuse des tisserandes raconte les entrelacements du masculin et du féminin, de la tragique histoire de Procné à la transgression d'Arachné.

L'exploration des relations entre hybridité et métamorphose fait ainsi ressortir les paradoxes de l'anthropocentrisme grec, conjugant une conception mouvante du monde à un désir irrésistible et permanent de franchissement des limites.

Véronique Dasen (Université de Fribourg)

Le Papyrus de Derveni, traduit et présenté par Fabienne Jourdan, Paris, Les Belles Lettres, 2003. 1 vol. $15 \times 21,5 \mathrm{~cm}$, XXII+166 p. (Vérité des mythes. Sources). ISBN : 2-251-32434-8.

Plus de quarante ans se sont désormais écoulés depuis la découverte dans une tombe de Derveni, non loin de Thessalonique, d'un rouleau de papyrus à demi consumé par le feu de l'incinération du défunt auquel il appartenait; et il y a plus de vingt ans que les philologues doivent se contenter de la transcription et de l'édition pirates de cet étrange commentaire du milieu du Iv ${ }^{e}$ siècle à une cosmo-théogonie explicitement attribuée à Orphée (ce texte provisoire a été prudemment cantonné dans une annexe à $Z P E, 47$ [1982], après p. 300 !). R. Janko vient de publier sous le titre «The Derveni Papyrus: an Interim Text », ZPE, 141 (2002) p. 1-62, un texte nouveau; il est assorti d'un apparat critique qui rend compte de manière relativement exhaustive des différentes conjectures proposées par les nombreux lecteurs du texte provisoire depuis vingt ans et d'une traduction qui peut remplacer celle offerte par A. Laks \& G. W. Most (éds), Studies in the Derveni Papyrus, Oxford, 1997, p. 9-22. Ce texte est très proche de celui désormais publié, avec une traduction, par G. Betegh, The Derveni Papyrus. Cosmology, Theology, and Interpretation, Cambridge, 2004, p. 4-55. Certes, l'apparat critique offert par le texte intérimaire publié par R. Janko intègre les leçons et conjectures transmises par K. Tsantsanoglou (l'éditeur du papyrus) notamment à A. Bernabé, lui-même l'auteur d'une édition toute récente des fragments orphiques (les fr. extraits du P. Derv. viennent d'être publiés dans le premier volume des Poetae epici Graeci. Testimonia et fragmenta, Pars II. Orphicorum et Orphicis similum testimonia et fragmenta, Fasc. 1, München/Leipzig, 2004); on ne saurait néanmoins en aucun cas prêter à ce texte établi tout récemment un statut définitif...

C'est dire que fournir l'étude d'un aspect du P. Derv. ou mieux encore en offrir un commentaire - que celui-ci soit consacré aux fragments de la cosmo-théogonie citée ou à son exégèse plus tardive - tient de la gageure. C'est donc le défi relevé par F. Jourdan qui présente pour la première fois aux érudits francophones le texte et la traduction du $P$. Derv. tel qu'il vient d'être publié (à quelques variations près) par R. Janko; texte et traduction sont assortis d'une introduction, d'une bibliographie, d'un 